\title{
New Synthetic Route to an Highly Efficient Photoredox Catalyst by Mechanosynthesis
}

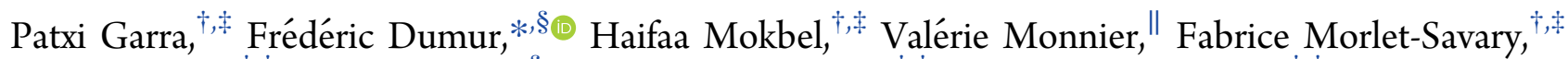

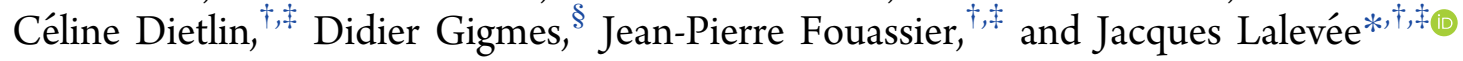

${ }^{\dagger}$ Université de Haute-Alsace, CNRS, IS2M UMR 7361, F-68100 Mulhouse, France

${ }^{\ddagger}$ Université de Strasbourg, Strasbourg 67081, France

${ }^{\S}$ Aix Marseille Univ, CNRS, ICR, UMR7273, F-13397 Marseille, France

"Aix Marseille Univ, CNRS, Fédération des Sciences Chimiques de Marseille, FR 1739 Marseille, France

\section{Supporting Information}

ABSTRACT: Photoredox catalysis based on the $[\mathrm{Cu}($ neo $)(\mathrm{DPEphos})] \mathrm{BF}_{4}$ copper complex allowed getting a significant improvement of the polymerization performances (e.g., thick samples, coatings...) compared to that obtained with other benchmarked photoinitiators in both cationic (CP) and free radical polymerizations (FRP). Nevertheless, as for other copper complexes classically used as photoinitiators in polymer science, the synthesis of these complexes is carried out in a solvent; this fact remains an obstacle to their widespread use because of the cost associated with the use of a solvent and the complex synthesis procedure. In the present study, on the contrary, an outstanding efficient mechanosynthesis of $[\mathrm{Cu}($ neo $)(\mathrm{DPEphos})] \mathrm{BF}_{4}-$ purity $\geq 95 \%$ outranking the previous $\mathrm{Cu}(\mathrm{I})$ mechanosynthesis-allowed (i) to divide the synthesis time by 170 -fold (as only $5 \mathrm{~min}$ is necessary to get the complex), (ii) to lower the environmental impact and cut the synthetic costs

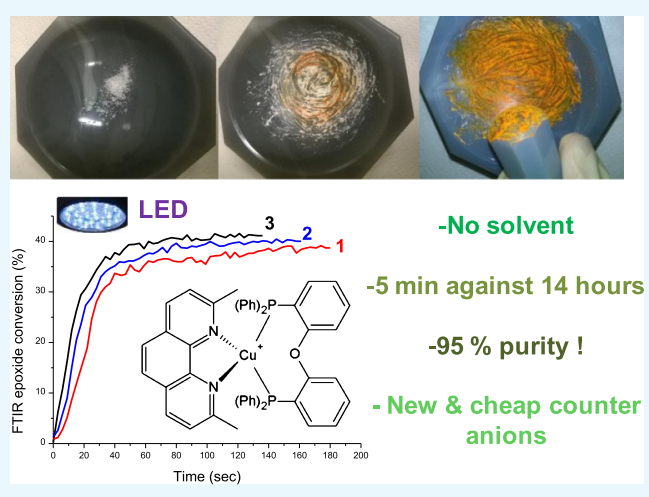
associated with solvent usage, and (iii) to access a new $\mathrm{Cu}(\mathrm{I})$ complex with a counteranion that is impossible to introduce under the traditional chemistry methods (e.g., $\mathrm{I}^{-}$). Reactivities of the mechanosynthesized copper complexes in resins (FRP and CP) confirmed the very high purity of the obtained copper complex by ${ }^{1} \mathrm{H}$ nuclear magnetic resonance spectroscopy and high-resolution electrospray ionization mass spectrometry.

\section{INTRODUCTION}

Photoinitiated free radical polymerization (FRP) and cationic polymerization $(\mathrm{CP})$ are techniques widely used in the industry for coatings, composites, inks, paintings, dentistry, and so forth. ${ }^{1-8}$ The development of photoinitiating systems (PISs) that can be activated with cheap and low-energy consumption light-emitting diodes (LEDs) has opened new perspectives in this field. ${ }^{9}$ In parallel, photoredox catalysis was proposed as an efficient strategy allowing to drastically reduce the amount of absorbing species in the PIS by regeneration of the photoredox catalyst. ${ }^{10,11}$ In this frame, copper-based PISs that can be activated with visible LEDs showed tremendous performances. $^{12,13} \mathrm{Cu}(\mathrm{I})$ bearing one diphosphine ligand (bis[2-(diphenylphosphino)phenyl]ether, noted DPEphos) and one diamine ligand (neocuproine, noted neo) will be referred as $[\mathrm{Cu}($ neo $)(\mathrm{DPEphos})] \mathrm{BF}_{4}$. Particularly, as shown in Table 1 , this $[\mathrm{Cu}($ neo $)(\mathrm{DPEphos})] \mathrm{BF}_{4}$ complex (see the structure in Scheme 1; will be noted as G1) was very active in thin films for FRP and CP under air, outperforming the bisacylphosphine oxide (BAPO) PIS. ${ }^{14}$ Next, the production of thick films (possible to obtain because a low amount of photoredox catalyst is used) was performed in CP; the resulting polymers were very stable toward thermolysis and hydrolysis, and these properties were assigned to the density of the polymer network and the high degree of conversion/crosslinking density (Table 1). Also, the introduction of a reducing agent $[\operatorname{tin}(\mathrm{II})$ complex] to regenerate the catalyst enabled (i) the FRP of low viscosity methacrylates upon sunlight irradiation, (ii) the full photopolymerization beyond light exposure (lateral photopolymerization $>29 \mathrm{~mm}$ ), and (iii) the complete curing of a $9 \mathrm{~cm}$ composite (45 wt \% fillers, full sample cured). More generally, copper complexes are of outmost importance in many aspects of polymer science. ${ }^{15-22}$ In the present paper, we propose to directly grind the copper precursor and the two ligands (see Scheme 1) to manually mechanosynthesize the G1 photoredox catalyst to enhance the easiness for its access.

Grinding or mechanosynthesis is a technique that was particularly used in the eighties. ${ }^{28}$ With regard to the pressing environmental issues in organic and inorganic chemistry, mechanosynthesis has received rather recently a strong revival of interest. $^{29,30}$ The mechanosynthesis of metal complexes

Received: July 9, 2018

Accepted: August 28, 2018

Published: September 10, 2018 
Table 1. Summary of the G1 Performance Compared with Published Literature References ${ }^{a}$

\begin{tabular}{|c|c|c|}
\hline photopolymerization application & previous reference & G1 PIS performance \\
\hline $\begin{array}{l}\text { FRP under LED@405 nm } \\
(25 \mu \mathrm{m} \text {, laminate })\end{array}$ & $\mathrm{FC}=53 \%$ for $\mathrm{BAPO}^{12}$ & $\mathrm{FC}=63 \%$ for $\mathrm{G} 1 / \operatorname{Iod}^{12}$ \\
\hline CP under LED@405 nm (25 $\mu \mathrm{m}$, air) & $\mathrm{FC}=40 \%$ for $\mathrm{BAPO} / \mathrm{Iod} / \mathrm{NVK}^{14}$ & $\mathrm{FC}=80 \%$ for $\mathrm{G} 1 / \mathrm{Iod} / \mathrm{NVK}^{14}$ \\
\hline $\begin{array}{l}\text { thick }(1.4 \mathrm{~mm}) \mathrm{CP} \text { under } \\
\text { LED@405 nm }\end{array}$ & $\begin{array}{l}>12 \text { wt } \% \text { weight loss at } 50 \mathrm{~h}, 75{ }^{\circ} \mathrm{C} \text { in water: degradation of the } \\
\text { polymer }\end{array}$ & $\begin{array}{l}<4 \text { wt } \% \text { weight loss at } 250 \mathrm{~h}, 75^{\circ} \mathrm{C} \text { in water: stable } \\
\text { polymer }\end{array}$ \\
\hline FRP under sunlight irradiation & high viscosity resins, $3 \mathrm{~min}$, under air $^{23}$ or glass laminates ${ }^{24}$ & low viscosity resin under air, $90 \mathrm{~s}^{25}$ \\
\hline lateral photopolymerization & $3.1 \mathrm{~mm}^{26}(\mathrm{MB} / \mathrm{DPI} / \mathrm{DIPEA})$ & $>29 \mathrm{~mm}^{25}$ \\
\hline composite photopolymerization & $2.9 \mathrm{~cm}$ thick $^{27}$ (acylphosphines) & $>9 \mathrm{~cm}$ thick $^{25}$ \\
\hline
\end{tabular}

${ }^{a} \mathrm{MB} / \mathrm{DPI} / \mathrm{DIPEA}$ stands for the initiating system: methylene blue/diphenyliodonium hexafluorophosphate/diisopropylethylamine in ref 25 . FC stands for final conversion.

Scheme 1. Summary of the Different Compounds and Abbreviations Used in This Article

\section{Cu(I) precursors}

$\mathrm{Cu}(\mathrm{ACN})_{4} \mathrm{BF}_{4}$

« G1 » Photoredox catalyst

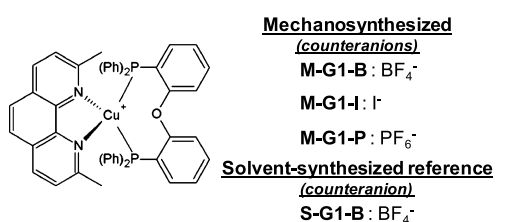

Oxidizing agent

$\mathrm{PF}_{6}^{-}$

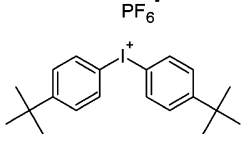

lod

Cul
$\mathrm{Cu}(\mathrm{ACN}){ }_{4} \mathrm{PF}_{6}$

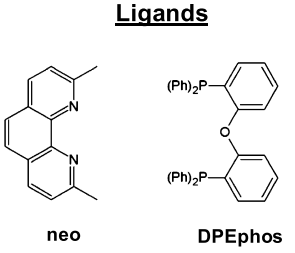

Additives

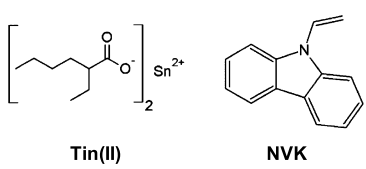

consists in grinding together the metal precursor and the associated ligands. Some studies have shown that the maximum energy present during grinding processes are in the range of $95-112 \mathrm{~kJ} \cdot \mathrm{mol}^{-1}$, corresponding approximately to temperatures in solution of $90^{\circ} \mathrm{C}$ (same mixing times)..$^{31,32}$ The excellent review by Do and Frišcic ${ }^{31}$ provides an overview of the different advantages of the mechanosynthetic routes, which are as follows: (i) no need of solvents at all (no emissions of volatile organic compounds and no solvent costs), (ii) no purification costs, and (iii) access to "impossible" compounds in solutions, that is, cannot be synthesized by use of traditional synthetic methods. Mechanosynthesis of copper complexes was recently studied by Kato and co-workers, ${ }^{30,33,34}$ but they had to use drops of solvents (also referred as solventassisted mechanochemistry ${ }^{29}$ ), and the yields remained below $65 \%$. Very few studies used mechanosynthesized products in polymer science. ${ }^{35-37}$ During the last year, our group reported two studies making use of mechanosynthesized copper complexes as redox FRP catalysts. ${ }^{38,39}$ However, the efficiency of the mechanosynthesis remained below $60 \%$ in the two cases (as in the literature).

Taking into account (i) the limitations/opportunities of mechanochemistry and (ii) the high interest of the G1 copper complex in photopolymerization, in the current study, we propose to mechanosynthesize the $\mathrm{G} 1$ complex from $\mathrm{Cu}(\mathrm{I})$ precursors bearing different counteranions $\left(\mathrm{PF}_{6}^{-}, \mathrm{BF}_{4}^{-}\right.$, and $\mathrm{I}^{-}$), as presented in Scheme 1: M-G1-P, M-G1-B, and M-G1-I. It is noteworthy that M-G1-I corresponds to the synthesis of a copper complex (with the iodide counteranion), which is impossible to realize in solution because of the insolubility of copper iodide in most of the common organic solvents. After characterization of the mechanosynthesized complex by nuclear magnetic resonance (NMR) $\left({ }^{1} \mathrm{H} \mathrm{NMR},{ }^{13} \mathrm{C} \mathrm{NMR}\right.$, and ${ }^{31} \mathrm{P}$ NMR) spectroscopy and high-resolution electrospray ionization mass spectrometry (HR-ESI-MS), the reactivity of the G1-based PIS was examined in light-assisted FRP, CP, and dual FRP/CP.

\section{EXPERIMENTAL SECTION}

2.1. Chemical Compounds. All reactants were used as received, and their structures are gathered in Scheme 1. Tetrakis(acetonitrile)copper(I) tetrafluoroborate $(\mathbf{C u}-$ $\left.(\mathbf{A C N})_{4} \mathbf{B F}_{4}\right)$, tetrakis(acetonitrile)copper(I) hexafluorophosphate $\left(\mathbf{C u}(\mathbf{A C N})_{4} \mathbf{P F}_{6}\right)$, tin 2-ethylhexanoate (tin(II)), copper(I) iodide (CuI), and neocuproine (neo) were purchased from Sigma-Aldrich. (Oxydi-2,1-phenylene)-bis(diphenylphosphine) (DPEphos) and $N$-vinylcarbazole (NVK) were purchased from Alfa Aesar. Di-tert-butyldiphenyl iodonium hexafluorophosphate (Iod) was obtained from Lambson Ltd. Deuterated chloroform was obtained from Eurisotop.

The efficiency of the different redox systems was checked in a model methacrylate mixture (see Scheme 2) with a low

Scheme 2. Benchmarked Methacrylate Resin (FRP) and Benchmarked Cationic Resin (EPOX, CP)
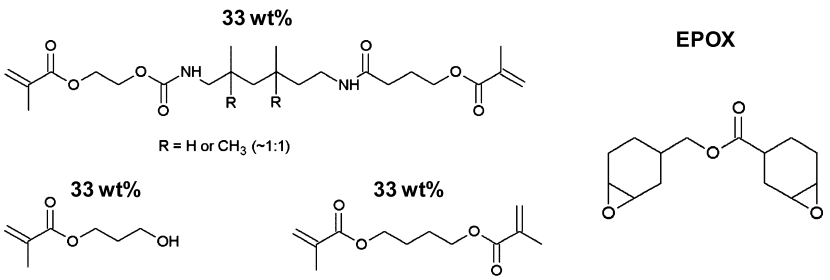

Model methacrylate resin

Model cationic resin

viscosity of $0.053 \mathrm{~Pa} \cdot \mathrm{s}$ containing 33.3 wt \% 1,4-butanedioldimethacrylate, $33.3 \mathrm{wt} \%$ hydroxypropylmethacrylate, and 33.3 wt \% urethane-dimethacrylate monomer (Sigma-Aldrich). The efficiency of the different redox cationic initiating systems was checked in (3,4-epoxycyclohexane)methyl 3,4-epoxycyclohexylcarboxylate (EPOX), which was obtained from Allnex (UVacure 1500).

2.2. Synthesis of the Copper Complexes. 2.2.1. Mechanosynthesis Protocols. Contrary to the previous mechanosynthesis of copper complexes ${ }^{30,33,40}$ where drops of solvents were added during and after the grinding procedure, no solvent at all was used in this study. First, $0.05 \mathrm{mmol} \mathrm{CuX}\left[\mathbf{C u}(\mathbf{A C N})_{4} \mathbf{B F}_{4}\right.$, 
$\mathbf{C u}(\mathrm{ACN})_{4} \mathbf{P F}_{6}$, or $\left.\mathbf{C u I}\right]$ and 1 equivalent of DPEphos were grinded in an agate mortar (VWR) with an agate pestle. The resulting solid was then grinded with 1 equivalent of neocuproine (neo) and analyzed using ${ }^{1} \mathrm{H}$ NMR, ${ }^{13} \mathrm{C}$ NMR, and ${ }^{31} \mathrm{P}$ NMR spectroscopies and HR-ESI-MS. The grinding times are described in the Results and Discussion section.

2.2.2. Synthesis of G1 in Solvent. The synthesis of S-G1-B was performed according to procedures already reported in the literature. ${ }^{12}$ The solvent used for the synthesis is dichloromethane (DCM, $14 \mathrm{~h}$ stirring in total) for the ligand exchange and pentane for the precipitation of G1.

2.3. HR-ESI-MS. Mass spectroscopy was performed by the Spectropole at Aix-Marseille University. ESI mass spectral analyses were recorded with a 3200 QTRAP (Applied Biosystems SCIEX) mass spectrometer. The HRMS analysis was performed with a QStar Elite (Applied Biosystems SCIEX) mass spectrometer. M-G1-X $\left(\mathrm{X}=\mathrm{PF}_{6}{ }^{-}, \mathrm{I}^{-}\right.$or $\left.\mathrm{BF}_{4}{ }^{-}\right)$was first dissolved in $450 \mu \mathrm{L}$ of DCM and then diluted at $1 / 10^{3}$ in a methanol solution containing $0.1 \mathrm{mM} \mathrm{NaCl}$. This solution was subsequently introduced in the ionization source at a flow rate of $10 \mu \mathrm{L} / \mathrm{min}$. Commercial polyethylene glycol (PEG600) was used as the internal standard. Raw HR-ESI-MS data are given in Table S1; they are summarized with the error between experimental and theoretical data in Table 3.

2.4. ${ }^{1} \mathrm{H}$ and ${ }^{31} \mathrm{P}$ NMR. ${ }^{1} \mathrm{H}$ and ${ }^{31} \mathrm{P}$ NMR spectra were recorded in $\mathrm{CDCl}_{3}$ solution on a $300 \mathrm{MHz}$ Varian Mercury spectrometer.

2.5. Photopolymerization Monitoring through Real Time Fourier transform infrared (RT-FTIR) Spectroscopy (Figures 2 and 3). A Jasco 6600 RT-FTIR spectrometer was used to record the $\mathrm{C}=\mathrm{C}$ double bond conversion and epoxide conversion versus time. The evolution of the near-infrared (NIR) methacrylate $\mathrm{C}=\mathrm{C}$ double bond peak followed at about $6170 \mathrm{~cm}^{-1}$. The evolution of the epoxide peak followed at the vibration around $3730 \mathrm{~cm}^{-1}$. Both NIR absorption polymerization monitoring techniques are widely applied in the polymerization science., ${ }^{3,9,10}$ LED@405 nm (Thorlabs; light intensity from 35 to $200 \mathrm{~mW} / \mathrm{cm}^{2}$ at the sample surface) was used for the photopolymerization experiments. The emission spectrum is already available in the literature. ${ }^{9,41}$ All experiments were carried out at room temperature under air. The equivalence in copper takes into account the different counteranion and $\mathrm{ACN}$ molecular weights, but they do not consider the purity of the complexes.

\section{RESULTS AND DISCUSSION}

3.1. Solvent-Free Synthesis of G1. The grinding procedure is described in Scheme 3. Copper(I) precursors $\left[\mathrm{Cu}(\mathrm{ACN})_{4} \mathrm{BF}_{4}\right.$ or $\mathbf{C u}(\mathrm{ACN})_{4} \mathrm{PF}_{6}$ or $\left.\mathrm{CuI}\right]$ were first grinded with the DPEphos ligand in reaction $\mathrm{r}$. DPEphos was selected as the first ligand to be introduced because of its bulkiness impeding the coordination of two ligands onto the metal

Scheme 3. Mechanosynthesis Route Proposed to Get M-G1$\mathrm{X}$ Starting From $\mathrm{CuX}\left[\mathrm{X}=\mathrm{I}^{-}\right.$or $(\mathrm{ACN})_{4} \mathrm{BF}_{4}{ }^{-}$or $(\mathrm{ACN})_{4} \mathrm{PF}_{6}{ }^{-}$. Structures Given in Scheme 1

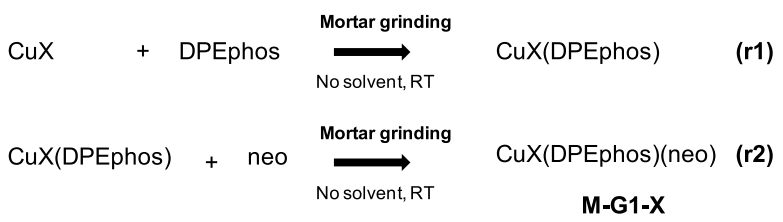

center. On the opposite, the coordination of two neocuproine ligands onto the $\mathrm{Cu}(\mathrm{I})$ center is well-established in the literature. One can see in Figure $1 \mathrm{~B}$ that for the mechanosynthesis of M-G1-I, it took around $4 \mathrm{~min}$ to obtain a homogeneous powder after $\mathrm{r} 1$; for the M-G1-B mechanosynthesis, it took only about $1 \mathrm{~min}$. For the coordination of the second ligand (neo, see reaction $\mathrm{r} 2$ ) in M-G1-B, the ligand addition occurred almost immediately after the beginning of the grinding as soon as a yellowish color appeared in the mortar. A similar strategy was applied for M-G1-P (see Figure $\mathrm{S} 1$ ). To have a completely yellow-orange color, it took about 5 min for both M-G1-P and M-G1-B. For copper iodide (CuI), the grinding time was longer (about $30 \mathrm{~min}$ in total) and stopped only when the yellow color was homogeneous.

To summarize (Table 2), we prepared M-G1-B, M-G1-I, and M-G1-P by mechanosynthesis of $\mathrm{Gl}$ using $\mathrm{BF}_{4}^{-}, \mathrm{I}^{-}$, and $\mathrm{PF}_{6}^{-}$counteranions, respectively. We also used the solventsynthesized $\mathrm{G} 1$ as the reference. It bears a $\mathrm{BF}_{4}{ }^{-}$counteranion: I will be noted S-G1-B. The color of the mechanosynthesized powders was orange for M-G1-P and M-G1-B, whereas yellow powders were obtained for S-G1-B and M-G1-I. When dissolved into a solvent, all complexes exhibited the characteristic yellow color of G1. The slightly orange color of M-G1-P and M-G1-B in powder was assigned to the presence of remaining traces of $\mathrm{ACN}$ [present in the initial copper(I) precursors]; these traces can be removed when the synthesis of these complexes is carried out in solution, the solvent being removed during the work-up. More importantly, for the present study, the reaction time for the complete synthesis of G1 was divided by a factor of 170 ! Indeed, M-G1-B is mechanosynthesized in about $5 \mathrm{~min}$ whereas $14 \mathrm{~h}$ are required for the synthesis of S-G1-B carried out in a solvent. Similarly, M-G1-P is accessible in about $4 \mathrm{~min} 30 \mathrm{~s}$. As estimated from the ${ }^{1} \mathrm{H}$ NMR integration of the remaining neo-free ligand versus the same proton peak in G1, the purities of M-G1-B ( $\geq 95 \%)$ and of M-G1-P ( $91 \%$ and $\geq 95 \%$ ) were outstandingly high (see Figure S2 in the Supporting Information). These reaction yields outperform - to the best of our knowledgethe yields previously reported for the mechanosynthesis of other copper complexes: (i) without any drops of solvent, about $60 \%$ yield was obtained for $\mathrm{Cu}(\mathrm{acac})(2 \mathrm{dppba})^{39}$ and (ii) when drops of solvents were added to the solvent-assisted mechanosynthesis of copper complexes, ${ }^{30,33,38,40}$ the yield was always below $65 \%$ [e.g., $60 \%$ for $\left[\mathrm{Cu}_{2}\left(\mathrm{CH}_{3} \mathrm{CN}\right)_{2}(\mathrm{dpypp})_{2}\right]$ $\left(\mathrm{BF}_{4}\right)_{2}{ }^{30}$ or $47 \%$ for $\left.\mathrm{CuBr}\left(\mathrm{PPh}_{3}\right)_{2}(4-\mathrm{Mepy})\right)^{33}$ We attributed this performance to the specific use of these two bidentate ligands having a strong affinity for the $\mathrm{Cu}(\mathrm{I})$ center.

In the case of M-G1-I, the purity of the complex was still high (between 70 and $72 \%$ ) though lower than that obtained for M-G1-B and M-G1-P. It can be assigned to the difficulty to dissociate the inorganic ligand $\left(\mathrm{I}^{-}\right)$from the metal center that impedes the coordination of the organic ligand. Nevertheless, the access to an iodide-based copper complex is of very high interest. Copper iodide is much cheaper than the other $\mathrm{Cu}(\mathrm{I})$ precursors. Also, importantly, such a synthesis would not be possible in solution as it would require very high temperatures to perform the ligand exchange.

In the literature, repeatability of the mechanosynthesis has always been discussed. ${ }^{30,33,38,40}$ Here, several syntheses were carried out, and similar purities were obtained. Also, no purification procedure at all was necessary for the obtained copper complexes, which significantly increases the interest of the strategy (see performances in Table 2). 


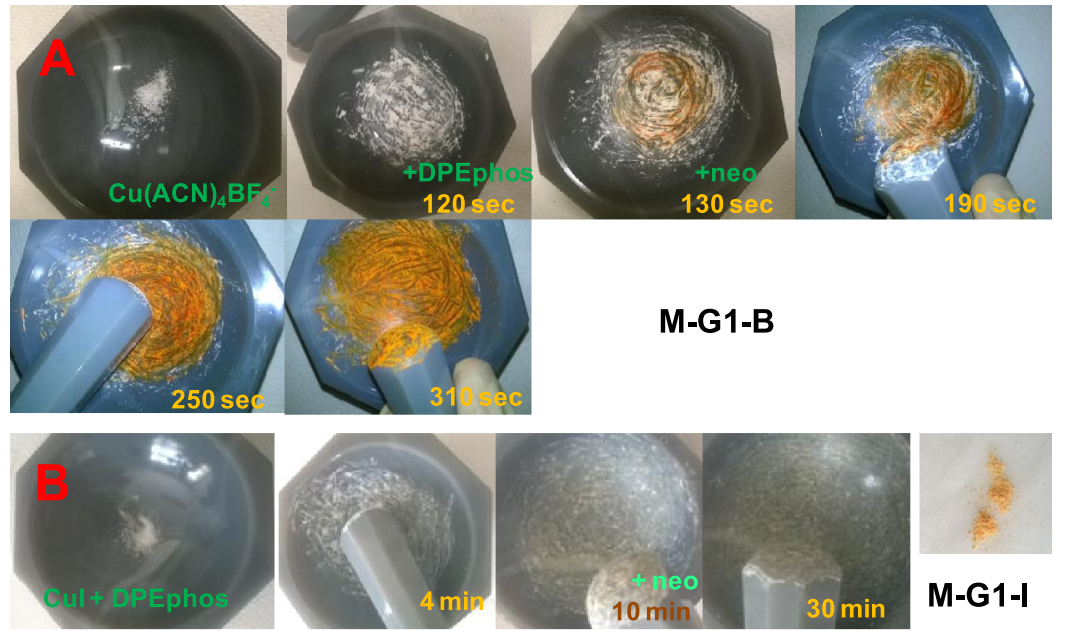

Figure 1. Bright-field images of M-G1-X mechanosynthesis. (A) M-G1-B was obtained from $\mathrm{Cu}(\mathrm{ACN})_{4} \mathrm{BF}_{4}$, DPEphos, and neo. (B) M-G1-I was obtained from CuI, DPEphos, and neo.

Table 2. Main Features of Solvent-Based Synthesis and Mechanosynthesis of G1 (Bearing Different Counteranions)

\begin{tabular}{|c|c|c|c|c|}
\hline G1 considered & $\begin{array}{l}\text { powder } \\
\text { color }\end{array}$ & $\begin{array}{l}\text { color in } \\
\text { solvent }^{a}\end{array}$ & $\begin{array}{l}\text { time for } \\
\text { synthesis }\end{array}$ & purity $^{b}$ \\
\hline S-G1-B & yellow & yellow & $\sim 14 \mathrm{~h}^{c}$ & $\begin{array}{l}\text { purified solid } \\
(\geq 95 \%)\end{array}$ \\
\hline M-G1-B & orange & yellow & $5 \mathrm{~min} 10 \mathrm{~s}$ & $\geq 95$ and $\geq 95 \%$ \\
\hline M-G1-I & yellow & yellow & $30 \mathrm{~min}$ & $\approx 72$ and $\approx 70 \%$ \\
\hline M-G1-P & orange & yellow & $4 \mathrm{~min} 30 \mathrm{~s}$ & $\approx 91$ and $\geq 95 \%$ \\
\hline
\end{tabular}

${ }^{a}$ Solvents tested: $\mathrm{CHCl}_{3}, \mathrm{DCM}$, and model methacrylate resin. ${ }^{b}$ Estimated from ${ }^{1} \mathrm{H}$ NMR integration (5\% quantification limit) between the reference G1 peaks and the neo-free ligand. Several experiments were carried out for each mechanosynthesis ${ }^{c}$ For solvent, adapted from Xiao et al. ${ }^{12}$

More characterizations of the mechanosynthesis were performed, as evidenced in Table 3. From ${ }^{1} \mathrm{H}$ NMR, ${ }^{13} \mathrm{C}$ NMR, and ${ }^{31} \mathrm{P}$ NMR spectra, all peaks characteristic of G1 (SG1-B) were present in the mechanosynthesized products (MG1-P and M-G1-B). Even more importantly, HR-ESI-MS unambiguously confirmed the presence of the G1 copper complexes with errors of less than 2 ppm for M-G1-P, M-G1-I, and M-G1-B molecular weights; the theoretical molecular weight of $809.1906 \mathrm{Da}$ was obtained for all these copper (I) complexes.

3.2. Photoinitiating Efficiency for FRP, $C P$, and Interpenetrating Polymer Network (IPN) Synthesis. Next, these differently prepared G1 complexes were tested in photopolymerization experiments (Figure 2). As M-G1-B and S-G1-B have the same counteranion, it is possible to directly compare them in CP. In Figure 2A, it can be observed that the kinetics for a G1/NVK/Iod system is almost exactly the same with about $40 \%$ conversion obtained after $40 \mathrm{~s}$ upon a low irradiance LED@405 nm (curve 1 for M-G1-B vs curve 2 for S-G1-B). This could be ascribed to the purity of M-G1-B that is very high ( ${ }^{1} \mathrm{H}$ NMR data) and competitive with that of $S$ G1-B. For M-G1-P and M-G1-I (also used without further purifications), the comparisons with S-G1-B were performed in photoinitiated FRP and are shown in Figure 2B. The counteranion is expected to have no influence on G1 reactivity in photoFRP. ${ }^{12,14}$ Very low concentrations of G1 and Iod were chosen to lower the reactivities, which will highlight the potential effects of the purities of the copper complexes. The kinetics for M-G1-P and S-G1-B were almost the same (80\% $\mathrm{C}=\mathrm{C}$ conversion after $30 \mathrm{~s}$ ), confirming the high purities observed in ${ }^{1} \mathrm{H}$ NMR. For M-G1-I, the kinetics is slightly less favorable with $75 \%$ conversion obtained after $100 \mathrm{~s}$, confirming the $70 \%$ purity obtained in Table 2 (lower effective G1 content). Nevertheless, this cheaper iodide-based G1 can be used in combination with tin(II) (see catalytic cycle in ref 25) for an outstandingly efficient photoinitiated FRP (15 s to reach $83 \%$ conversion).

Then, in Figure 2C, the comparison between M-G1-P (curve 1) and S-G1-B (curve 2) photoinitiating efficiencies was carried out turning the LED irradiance to a very low value of $35 \mathrm{~mW} / \mathrm{cm}^{2}$. Indeed, when irradiances are lower, the light absorbed intensity by the PIS (also referred as $I_{\text {abs }}$ ) is considerably lowered, which will enhance the ratio between inhibitions (e.g., oxygen inhibition ${ }^{42,43}$ ) and initiating radical generations. Doing so, radical generation rates (or photopolymerization efficiencies) will be even more sensitive to impurities in the PIS. Very interestingly, the results appearing in Figure 2B are confirmed in Figure 2C: M-G1-P and S-G1-B show exactly the same photoinitiating abilities, which confirm the $\mathrm{Cu}(\mathrm{I})$ purities obtained by mechanosynthesis.

Table 3. NMR and HR-ESI-MS Determination of the Cu(I) Synthesized

$\begin{array}{cc}\text { G1 considered } & { }^{1} \mathrm{H} \text { NMR presence of } \mathrm{G} 1 \text { peaks } \\ \text { S-G1-B } & \text { reference }^{b} \\ \text { M-G1-B } & \sqrt{ } \\ \text { M-G1-I } & \sqrt{ } \\ \text { M-G1-P } & \sqrt{ }\end{array}$

${ }^{13}$ C NMR presence of G1 peaks
reference ${ }^{b}$
$\sqrt{ }$
$\sqrt{ }$
$\sqrt{ }$

${ }^{31} \mathrm{P}$ NMR presence of $\mathrm{G} 1$ peaks
reference ${ }^{b}$
$\sqrt{ }$
$\sqrt{ }$
$\sqrt{ }$

HR-ESI-MS $\left[\mathrm{M}^{+}\right]^{a}$ 809.1906 Da 809.1906 Da $( \pm 2 \mathrm{ppm})$ $809.1906 \mathrm{Da}( \pm 1 \mathrm{ppm})$ $809.1906 \mathrm{Da}( \pm 1 \mathrm{ppm})$

${ }^{a}$ theoretical: 809.1906 Da. Reference from. ${ }^{12}$ See experimental data of HR-ESI-MS in Table S1. ${ }^{b}$ From ref 12. 

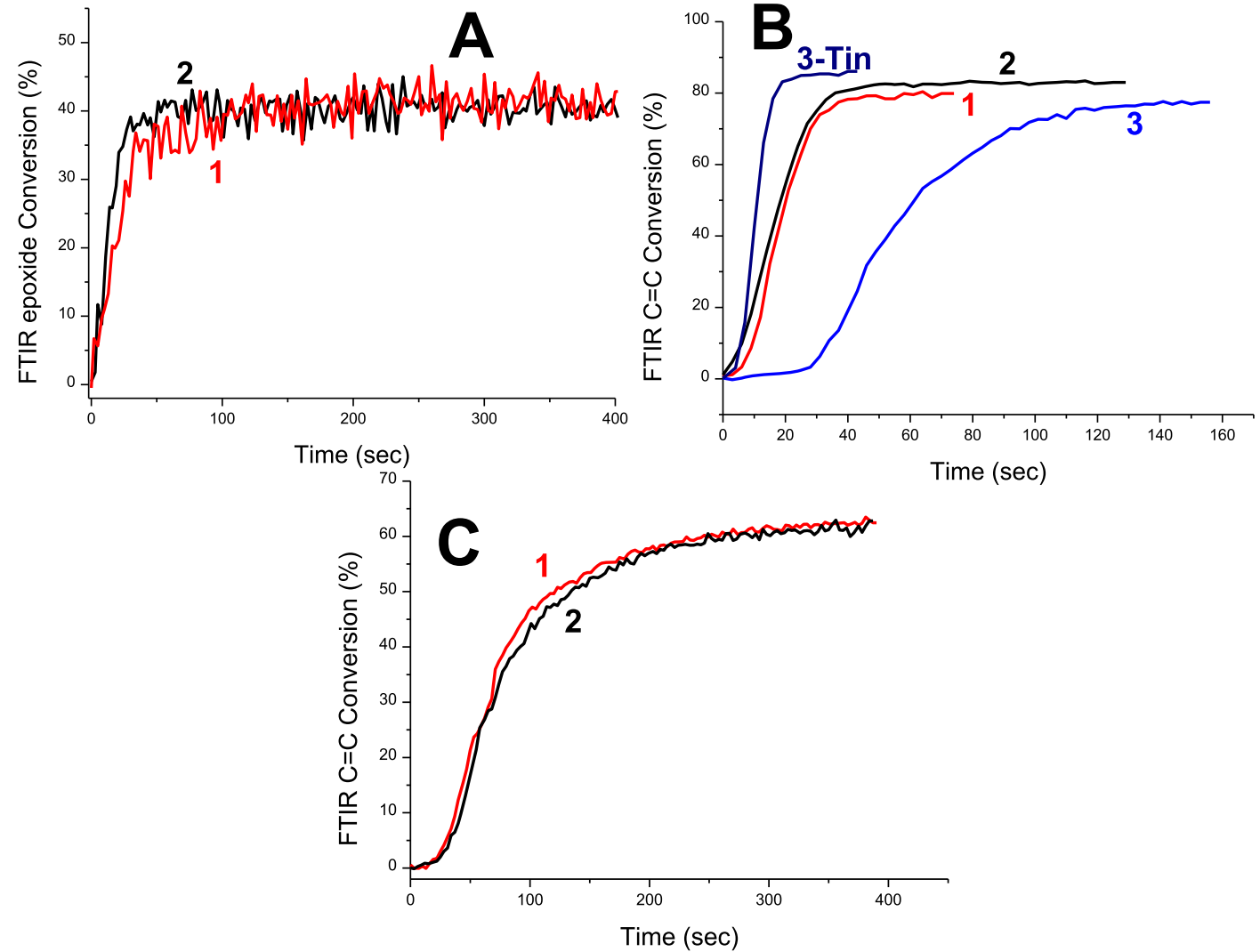

Figure 2. RT-FTIR polymerization profiles (reactive function conversion vs time) under air. (A) EPOX (CP) upon exposure to LED@405 nm $\left(200 \mathrm{~mW} / \mathrm{cm}^{2}\right)$ for $2 \mathrm{wt} \%$ Iod, $2 \mathrm{wt} \% \mathrm{NVK}$, and (1) $0.4 \mathrm{wt} \% \mathrm{M}-\mathrm{G} 1-\mathrm{B}$ or (2) 1 equiv S-G1-B. (B,C)Methacrylate resin (FRP) (B)upon exposure to LED@405 nm $\left(110 \mathrm{~mW} / \mathrm{cm}^{2}\right)$ for $0.8 \mathrm{wt} \%$ Iod and (1) $0.3 \mathrm{wt} \%$ M-G1-P or (2) 1 equiv S-G1-B or (3) 1 equiv M-G1-I or (3-tin) 1 equiv MG1-I and 5 wt \% tin(II) and (C) upon exposure to LED@405 nm $\left(35 \mathrm{~mW} / \mathrm{cm}^{2}\right)$ for $0.8 \mathrm{wt} \%$ Iod and (1) $0.3 \mathrm{wt} \%$ M-G1-P or (2) 1 equiv S-G1-B.
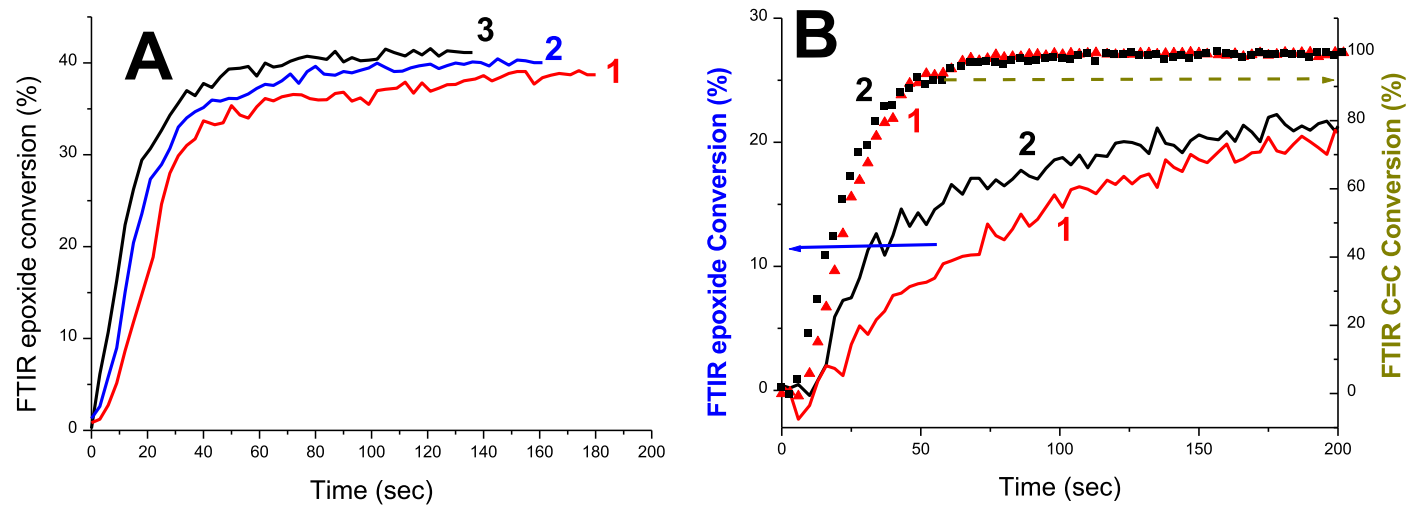

Figure 3. RT-FTIR polymerization profiles (reactive function conversion vs time) under air. (A)For EPOX (CP), upon exposure to LED@405 nm $\left(110 \mathrm{~mW} / \mathrm{cm}^{2}\right)$ for $4 \mathrm{wt} \%$ Iod, 1 wt \% NVK, and (1) $0.8 \mathrm{wt} \% \mathrm{M}-\mathrm{G} 1-\mathrm{I}$ or (2) 1 equiv M-G1-B or (3) 1 equiv M-G1-P. (B)For an EPOX/ methacrylate blend $(80 / 20 \mathrm{w} / \mathrm{w})$ (dual CP/FRP), upon exposure to LED@405 nm $\left(110 \mathrm{~mW} / \mathrm{cm}^{2}\right)$ for $2 \mathrm{wt} \%$ Iod and (1) 0.4 wt \% S-G1-B or (2) 1 equiv M-G1-P.

Finally, the current report enables the study of new types of counteranions of G1 in cationic photopolymerization. In Figure 3A, M-G1-P (not yet mentioned/accessed in the previous G1 studies) was the best copper complex with $40 \%$ epoxide conversion after $40 \mathrm{~s}$ (curve 3, Figure 3A). Next, MG1-B showed slightly slower kinetics (38\% epoxide conversion after $45 \mathrm{~s}$, curve 2, Figure 3A) when M-G1-I was the less efficient copper complex (35\% conversion after $50 \mathrm{~s}$, curve 1 , Figure $3 \mathrm{~A})$. This order of reactivity was attributed to the nucleophilicity of the counteranion: $\mathrm{PF}_{6}{ }^{-}$is less nucleophilic followed by $\mathrm{BF}_{4}^{-}$; $\mathrm{I}^{-}$shows the highest nucleophilicity with a more localized negative charge. Such a counteranion is likely to trap the propagating cations. This effect of the counteranion is in line with the well-known literature. ${ }^{44}$

The access to M-G1-P (new counteranion) also offers better performances in the IPN synthesis: in Figure 3B, one can see that the kinetics for epoxide conversion was greatly enhanced when comparing M-G1-P with S-G1-B; $10 \%$ epoxide conversion after $75 \mathrm{~s}$ for S-G1-B (curve 2) when $17 \%$ epoxide conversion is possible with M-G1-P (curve 1). The $\mathrm{C}=\mathrm{C}$ conversion kinetics was-logically-less affected by the 
change of the counteranion. Tack-free polymers were obtained in both cases.

\section{CONCLUSIONS}

The mechanosynthesis of an outstandingly efficient photoredox catalyst for photopolymerization initiation is proposed. Very interestingly, the mechanosynthesis of G1 was very efficient with more than $95 \%$ purity $\left({ }^{1} \mathrm{H}\right.$ NMR data) when most of the copper complexes mechanosynthesized previously had purities below 65\%. FRP and CP photopolymerization tests fully confirmed the purities encountered in the ${ }^{1} \mathrm{H}$ NMR data. Also, the access to a new cheaper $\mathrm{Cu}(\mathrm{I})$ counteranion was possible $\left(\mathrm{I}^{-}\right)$. Interestingly, a G1-bearing $\mathrm{PF}_{6}^{-}$counteranion was also prepared, which can be very interesting in $\mathrm{CP}$ because of the lower nucleophilicity of $\mathrm{PF}_{6}{ }^{-}$. The use of mechanosynthesis for other PISs of high interest will be presented in forthcoming papers.

\section{ASSOCIATED CONTENT}

\section{S Supporting Information}

The Supporting Information is available free of charge on the ACS Publications website at DOI: 10.1021/acsomega.8b01586.

Bright-field images of M-G1-P mechanosynthesis; superimposed ${ }^{1} \mathrm{H}$ NMR spectra of neocuproine, DPEPhos, and mechanosynthesized M-G1-B complex; and experimental data acquired in HR-ESI-MS (PDF)

\section{AUTHOR INFORMATION}

\section{Corresponding Authors}

*E-mail: frederic.dumur@univ-amu.fr (F.D.).

*E-mail: jacques.lalevee@uha.fr (J.L.).

ORCID

Frédéric Dumur: 0000-0003-4872-094X

Jacques Lalevée: 0000-0001-9297-0335

Notes

The authors declare no competing financial interest.

\section{ACKNOWLEDGMENTS}

The authors wish to thank the Agence Nationale de la Recherche for the grant "FastPrinting."

\section{REFERENCES}

(1) Lalevée, J.; Fouassier, J.-P. Dyes and Chomophores in Polymer Science; John Wiley \& Sons, 2015.

(2) Fouassier, J.-P.; Rabek, J. F. Radiation Curing in Polymer Science and Technology; Springer Science \& Business Media, 1993.

(3) Fouassier, J.-P.; Lalevée, J. Photoinitiators for Polymer Synthesis: Scope, Reactivity, and Efficiency; John Wiley \& Sons, 2012.

(4) Neckers, D. C.; Jager, W.; SITA Technology Limited. Chemistry \& Technology for UV \& EB Formulation for Coatings, Inks \& Paints, Photoinitiation for Polymerization: UV \& EB at the Millenium; Wiley: Chichester, 1999.

(5) Rutsch, W.; Dietliker, K.; Leppard, D.; Köhler, M.; Misev, L.; Kolczak, U.; Rist, G. Recent Developments in Photoinitiators. Prog. Org. Coat. 1996, 27, 227-239.

(6) Crivello, J. V.; Dietliker, K. Photoinitiators for Free Radical Cationic \& Anionic Photopolymerisation; Wiley, 1999.

(7) Dietliker, K. A Compilation of Photoinitiators Commercially Available for UV Today; SITA Technology Limited, 2002.

(8) Garra, P.; Dietlin, C.; Morlet-Savary, F.; Dumur, F.; Gigmes, D.; Fouassier, J.-P.; Lalevée, J. Photopolymerization Processes of Thick
Films and in Shadow Areas: A Review for the Access to Composites. Polym. Chem. 2017, 8, 7088-7101.

(9) Dietlin, C.; Schweizer, S.; Xiao, P.; Zhang, J.; Morlet-Savary, F.; Graff, B.; Fouassier, J.-P.; Lalevee, J. Photopolymerization upon LEDs: New Photoinitiating Systems and Strategies. Polym. Chem. 2015, 6, 3895-3912.

(10) Zivic, N.; Bouzrati-Zerelli, M.; Kermagoret, A.; Dumur, F.; Fouassier, J.-P.; Gigmes, D.; Lalevée, J. Photocatalysts in Polymerization Reactions. ChemCatChem 2016, 8, 1617-1631.

(11) Corrigan, N.; Shanmugam, S.; Xu, J.; Boyer, C. Photocatalysis in Organic and Polymer Synthesis. Chem. Soc. Rev. 2016, 45, 61656212.

(12) Xiao, P.; Dumur, F.; Zhang, J.; Fouassier, J. P.; Gigmes, D.; Lalevée, J. Copper Complexes in Radical Photoinitiating Systems: Applications to Free Radical and Cationic Polymerization upon Visible LEDs. Macromolecules 2014, 47, 3837-3844.

(13) Mousawi, A. A.; Kermagoret, A.; Versace, D.-L.; Toufaily, J.; Hamieh, T.; Graff, B.; Dumur, F.; Gigmes, D.; Fouassier, J. P.; Lalevée, J. Copper Photoredox Catalysts for Polymerization upon near UV or Visible Light: Structure/Reactivity/Efficiency Relationships and Use in LED Projector 3D Printing Resins. Polym. Chem. 2016, 8, 568-580.

(14) Mokbel, H.; Anderson, D.; Plenderleith, R.; Dietlin, C.; MorletSavary, F.; Dumur, F.; Gigmes, D.; Fouassier, J.-P.; Lalevée, J. Copper photoredox catalyst G1: a new high performance photoinitiator for near-UV and visible LEDs. Polym. Chem. 2017, 8, 5580-5592.

(15) Wu, P.; Feldman, A. K.; Nugent, A. K.; Hawker, C. J.; Scheel, A.; Voit, B.; Pyun, J.; Fréchet, J. M. J.; Sharpless, K. B.; Fokin, V. V. Efficiency and Fidelity in a Click-Chemistry Route to Triazole Dendrimers by the Copper(I)-Catalyzed Ligation of Azides and Alkynes. Angew. Chem. 2004, 116, 4018-4022.

(16) Jiang, X.; Wu, J.; Zhang, L.; Cheng, Z.; Zhu, X. Highly Active Ppm Level Organic Copper Catalyzed Photo-Induced ICAR ATRP of Methyl Methacrylate. Macromol. Rapid Commun. 2014, 35, 18791885.

(17) Waldron, C.; Zhang, Q.; Li, Z.; Nikolaou, V.; Nurumbetov, G.; Godfrey, J.; McHale, R.; Yilmaz, G.; Randev, R. K.; Girault, M.; et al. Absolut "Copper Catalyzation Perfected"; Robust Living Polymerization of NIPAM: Guinness Is Good for SET-LRP. Polym. Chem. 2013, 5, 57-61.

(18) Haddleton, D. M.; Jasieczek, C. B.; Hannon, M. J.; Shooter, A. J. Atom Transfer Radical Polymerization of Methyl Methacrylate Initiated by Alkyl Bromide and 2-Pyridinecarbaldehyde Imine Copper(I) Complexes. Macromolecules 1997, 30, 2190-2193.

(19) Wenn, B.; Conradi, M.; Carreiras, A. D.; Haddleton, D. M.; Junkers, T. Photo-Induced Copper-Mediated Polymerization of Methyl Acrylate in Continuous Flow Reactors. Polym. Chem. 2014, 5, 3053-3060.

(20) Song, H. B.; Baranek, A.; Bowman, C. N. Kinetics of bulk photo-initiated copper(i)-catalyzed azide-alkyne cycloaddition (CuAAC) polymerizations. Polym. Chem. 2016, 7, 603-612.

(21) Tasdelen, M. A.; Yilmaz, G.; Iskin, B.; Yagci, Y. Photoinduced Free Radical Promoted Copper(I)-Catalyzed Click Chemistry for Macromolecular Syntheses. Macromolecules 2012, 45, 56-61.

(22) Garra, P.; Dumur, F.; Morlet-Savary, F.; Dietlin, C.; Fouassier, J. P.; Lalevée, J. A New Highly Efficient Amine-Free and PeroxideFree Redox System for Free Radical Polymerization under Air with Possible Light Activation. Macromolecules 2016, 49, 6296-6309.

(23) Lalevée, J.; Fouassier, J. P. Recent advances in sunlight induced polymerization: role of new photoinitiating systems based on the silyl radical chemistry. Polym. Chem. 2011, 2, 1107-1113.

(24) Decker, C.; Zahouily, K.; Decker, D.; Nguyen, T.; Viet, T. Performance Analysis of Acylphosphine Oxides in Photoinitiated Polymerization. Polymer 2001, 42, 7551-7560.

(25) Garra, P.; Dumur, F.; Gigmes, D.; Al Mousawi, A.; MorletSavary, F.; Dietlin, C.; Fouassier, J. P.; Lalevée, J. Copper (Photo)Redox Catalyst for Radical Photopolymerization in Shadowed Areas and Access to Thick and Filled Samples. Macromolecules 2017, 50, 3761-3771. 
(26) Aguirre-Soto, A.; Lim, C.-H.; Hwang, A. T.; Musgrave, C. B.; Stansbury, J. W. Visible-Light Organic Photocatalysis for Latent Radical-Initiated Polymerization via $2 \mathrm{e}-/ 1 \mathrm{H}+$ Transfers: Initiation with Parallels to Photosynthesis. J. Am. Chem. Soc. 2014, 136, 74187427.

(27) Narayanan, V.; Baikerikar, K. K.; Scranton, A. B. A Study of Initiating Systems for Photopolymerization of Composites; Radtech Int North America: Northbrook, 1998.

(28) Garay, A. L.; Pichon, A.; James, S. L. Solvent-Free Synthesis of Metal Complexes. Chem. Soc. Rev. 2007, 36, 846-855.

(29) Bowmaker, G. A. Solvent-Assisted Mechanochemistry. Chem. Commun. 2013, 49, 334-348.

(30) Kobayashi, A.; Hasegawa, T.; Yoshida, M.; Kato, M. Environmentally Friendly Mechanochemical Syntheses and Conversions of Highly Luminescent $\mathrm{Cu}(\mathrm{I})$ Dinuclear Complexes. Inorg. Chem. 2016, 55, 1978-1985.

(31) Do, J.-L.; Friščić, T. Mechanochemistry: A Force of Synthesis. ACS Cent. Sci. 2017, 3, 13-19.

(32) McKissic, K. S.; Caruso, J. T.; Blair, R. G.; Mack, J. Comparison of Shaking versus Baking: Further Understanding the Energetics of a Mechanochemical Reaction. Green Chem. 2014, 16, 1628.

(33) Ohara, H.; Kobayashi, A.; Kato, M. Simple and Extremely Efficient Blue Emitters Based on Mononuclear $\mathrm{Cu}(\mathrm{I})$-Halide Complexes with Delayed Fluorescence. Dalton Trans. 2014, 43, 17317-17323.

(34) Kobayashi, A.; Kato, M. Stimuli-Responsive Luminescent Copper(I) Complexes for Intelligent Emissive Devices. Chem. Lett. 2017, 46, 154-162.

(35) Glassner, M.; Maji, S.; de la Rosa, V. R.; Vanparijs, N.; Ryskulova, K.; De Geest, B. G.; Hoogenboom, R. Solvent-Free Mechanochemical Synthesis of a Bicyclononyne Tosylate: A Fast Route towards Bioorthogonal Clickable Poly(2-Oxazoline)S. Polym. Chem. 2015, 6, 8354-8359.

(36) Makhaev, V. D.; Galiullin, A. N.; Faingol'd, E. E.; Bravaya, N. M.; Petrova, L. A. Mechanochemical Synthesis of Triphenylmethylium and Triphenylcyclopropenylium Tetrakis(Pentafluorophenyl)Borates. Russ. Chem. Bull. 2014, 63, 651-656.

(37) Makhaev, V. D.; Petrova, L. A.; Bravaya, N. M.; Faingol'd, E. E.; Mukhina, E. V.; Panin, A. N.; Gagieva, S. C.; Tuskaev, V. A.; Bulychev, B. M. Mechanochemical synthesis of zirconium and hafnium phenoxyimine complexes $\mathrm{L} 2 \mathrm{MCl} 2(\mathrm{~L}=\mathrm{N}$-(3,5-di-tertbutylsalicylidene)-2,3,5,6-tetrafluoroanilinate anion) and their catalytic properties in ethylene polymerization. Russ. Chem. Bull. 2014, 63, $1533-1538$.

(38) Garra, P.; Dumur, F.; Al Mousawi, A.; Graff, B.; Gigmes, D.; Morlet-Savary, F.; Dietlin, C.; Fouassier, J. P.; Lalevée, J. Mechanosynthesized Copper(I) Complex Based Initiating Systems for Redox Polymerization: Towards Upgraded Oxidizing and Reducing Agents. Polym. Chem. 2017, 8, 5884-5896.

(39) Garra, P.; Dumur, F.; Morlet-Savary, F.; Dietlin, C.; Gigmes, D.; Fouassier, J. P.; Lalevée, J. Mechanosynthesis of a Copper Complex for Redox Initiating Systems with a Unique near Infrared Light Activation. J. Polym. Sci., Part A: Polym. Chem. 2017, 55, 36463655.

(40) Zeng, C.; Wang, N.; Peng, T.; Wang, S. Copper(I) Complexes Bearing 1,2-Phenyl-Bridged $\mathrm{P} \wedge \mathrm{N}, \mathrm{P} \wedge \mathrm{N} \wedge \mathrm{P}$, and $\mathrm{N} \wedge \mathrm{P} \wedge \mathrm{N}$ Chelate Ligands: Structures and Phosphorescence. Inorg. Chem. 2017, 56, $1616-1625$.

(41) Morlet-Savary, F.; Klee, J. E.; Pfefferkorn, F.; Fouassier, J. P.; Lalevée, J. The Camphorquinone/Amine and Camphorquinone/ Amine/Phosphine Oxide Derivative Photoinitiating Systems: Overview, Mechanistic Approach, and Role of the Excitation Light Source. Macromol. Chem. Phys. 2015, 216, 2161-2170.

(42) Ligon, S. C.; Husár, B.; Wutzel, H.; Holman, R.; Liska, R. Strategies to Reduce Oxygen Inhibition in Photoinduced Polymerization. Chem. Rev. 2014, 114, 557-589.

(43) Husár, B.; Ligon, S. C.; Wutzel, H.; Hoffmann, H.; Liska, R. The formulator's guide to anti-oxygen inhibition additives. Prog. Org. Coat. 2014, 77, 1789-1798.
(44) Crivello, J. V. The Discovery and Development of Onium Salt Cationic Photoinitiators. J. Polym. Sci., Part A: Polym. Chem. 2000, 37, $4241-4254$. 